\title{
TRANSIENT LIQUID PHASE BEHAVIOR OF Sn-COATED Cu PARTICLES AND CHIP BONDING USING PASTE CONTAINING THE PARTICLES
}

\begin{abstract}
Sn-coated $\mathrm{Cu}$ particles were prepared as a filler material for transient liquid phase (TLP) bonding. The thickness of Sn coating was controlled by controlling the number of plating cycles. The Sn-coated Cu particles best suited for TLP bonding were fabricated by Sn plating thrice, and the particles showed a pronounced endothermic peak at $232^{\circ} \mathrm{C}$. The heating of the particles for just $10 \mathrm{~s}$ at $250^{\circ} \mathrm{C}$ destroyed the initial core-shell structure and encouraged the formation of $\mathrm{Cu}-\mathrm{Sn}$ intermetallic compounds. Further, die bonding was also successfully performed at $250^{\circ} \mathrm{C}$ under a slight bonding pressure of around $0.1 \mathrm{MPa}$ using a paste containing the particles. The bonding time of $30 \mathrm{~s}$ facilitated the bonding of $\mathrm{Sn}$-coated $\mathrm{Cu}$ particles to the Au surface and also increased the probability of network formation between particles.

Keywords: Sn-coated $\mathrm{Cu}$, immersion plating, chip bonding, transient liquid phase (TLP) sintering, intermetallic compounds (IMC)
\end{abstract}

\section{Introduction}

With the extensive application of power modules containing silicon carbide ( $\mathrm{SiC}$ ) chips, the need for bonding materials that can withstand extremely high operating temperatures and do not melt has increased [1]. Although high-temperature solder alloys are preferential candidates, they are not used in the electronics industry due to their high-temperature bonding conditions, reliability issues, and absence of unique properties [2]. Ag nanoparticles, though very popular in the electronics industry, require very long sintering durations at temperatures of around $250^{\circ} \mathrm{C}$ [3]. In addition, a transient liquid phase (TLP) bonding method using a solder layer such as Sn sandwiched between high conductive and cost-effective metal layers such as $\mathrm{Cu}$ is considered to be an alternative method that can possess sufficient reliability [4-6]. The solder melted at an appropriate temperature reacts with $\mathrm{Cu}$ to form intermetallic compounds (IMC), which are capable of withstanding temperatures higher than the reaction temperature. However, the TLP bonding requires high temperature and long bonding time. For example, to transform the molten Sn layer into solid intermetallic layers in the sandwiched bondline, the bonding time required at $340^{\circ} \mathrm{C}$ was $90 \mathrm{~min}$.

In this study, chip bonding was conducted by TLP sintering using $\mathrm{Sn}$-coated $\mathrm{Cu}$ particles. Significantly, when compared to earlier TLP bonding methods [7], the inclusion of particles results in the formation of a relatively uniform bondline structure at low magnification. Moreover, the core/shell particles will remarkably decrease the TLP bonding time at relatively low temperature because particles with this structure can reduce the time required for the completion of the reaction between molten $\mathrm{Sn}$ and $\mathrm{Cu}$.

\section{Materials and methods}

Sn coating on spherical Cu particles was accomplished using immersion plating. To prepare the Sn plating solution, $0.0158 \mathrm{~mol}$ of tin(II) chloride ( $\mathrm{SnCl}$, Sigma-Aldrich, 98\%) and $0.0788 \mathrm{~mol}$ of thiourea ( $\mathrm{SC}\left(\mathrm{NH}_{2}\right)_{2}$, Samchun chemicals, 98\%) were added to $50 \mathrm{~mL}$ of ethylene glycol $\left(\left(\mathrm{CH}_{2} \mathrm{OH}\right)_{2}, 99.7 \%\right.$, SK networks $)$. All the chemicals were mixed in a beaker by stirring, on a hot plate maintained at $65^{\circ} \mathrm{C}$. Meanwhile, $5 \mathrm{~g}$ of spherical $\mathrm{Cu}$ powder (99.64\%, average particle size: $2 \mu \mathrm{m}$, JoinM) was dispersed at $65^{\circ} \mathrm{C}$ in $50 \mathrm{~mL}$ of ethylene glycol in another beaker; once the particles were dispersed well, the $\mathrm{Cu}$ powder solution was added to the plating solution and the mixture was continuously stirred for $5 \mathrm{~min}$ at $65^{\circ} \mathrm{C}$. Further, the plating step was performed once, twice, and thrice to obtain particles with Sn shells of different thicknesses. After sedimentation of the plated particles, the supernatant was decanted off and the beaker was refilled with distilled water. This step of decantation and washing with distilled water was repeated three times. The sediment was collected and washed with ethyl alcohol, followed by drying in a vacuum chamber.

The cross-sectional microstructure of the fabricated Sn-coated $\mathrm{Cu}$ particles was observed with scanning electron microscopy (SEM, VEGA 3 LMU, TESCAN Ltd.) using the back-scattered electron (BSE) mode. While energy-dispersive 
spectroscopy (EDS, 4502A-3UES-SN, Thermo) was used to analyze the composition of the fabricated particles, differential scanning calorimetry (DSC, Q20, TA Instruments, Inc.) was used to analyze their thermal characteristics. The content variation of elements within a cross-section of the sample was verified using a field emission electron probe micro analyzer (EPMA, JXA-8530F, JEOL Ltd). In order to understand the phase transformation during heating, X-ray diffraction (XRD, D 8 Focus, Bruker AXS GMBH) was also conducted.

A paste was prepared by mixing the $\mathrm{Sn}$-coated $\mathrm{Cu}$ particles with a commercial flux (KS-ST22, Koki Korea Co, Ltd.) at a 9:1 ratio. This paste was then sandwiched between an Au-plated substrate and an Au-plated chip, in order to achieve chip bonding.

\section{Results and discussions}

Figure 1 shows cross-sectional BSE images of Sn-coated $\mathrm{Cu}$ particles prepared using different numbers of plating cycles.
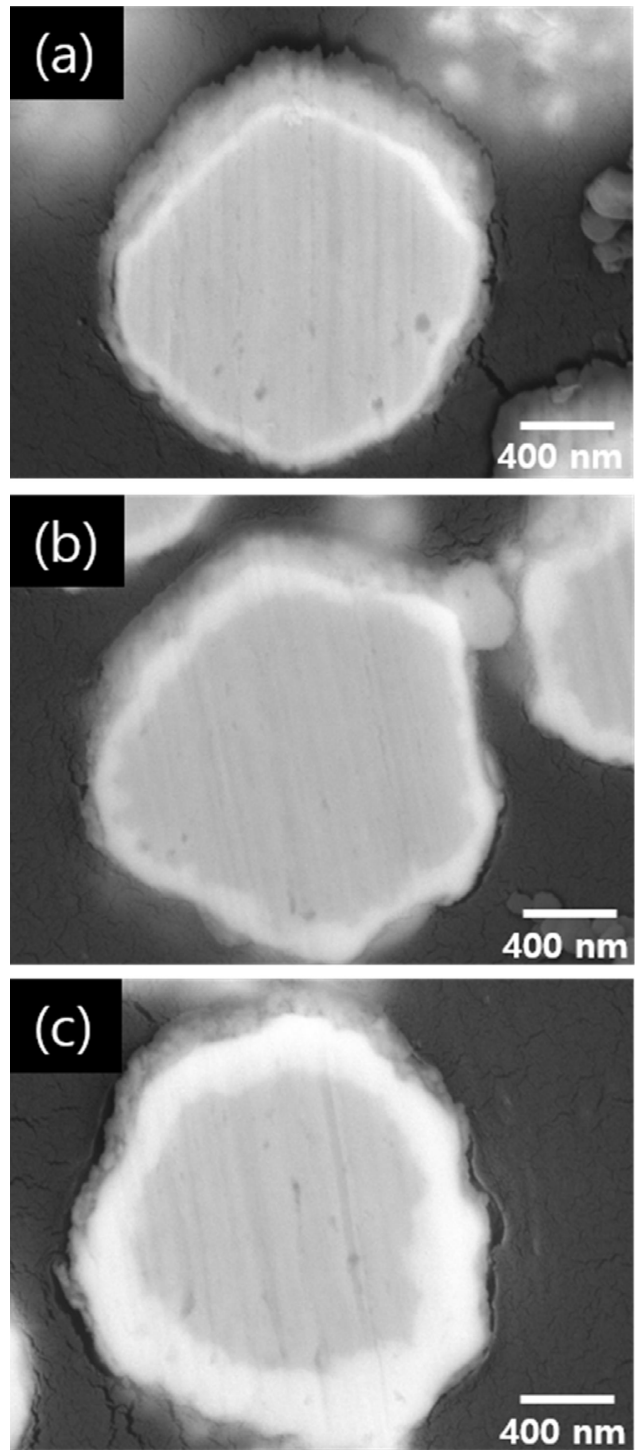

Fig. 1. Cross-sectional BSE images of Sn-coated Cu particles prepared with different number of plating cycles: (a) 1 time, (b) 2 times, and (c) 3 times
While the gray region at the core indicates a pure $\mathrm{Cu}$ phase, the white region at the edge represents a pure Sn phase. The images clearly show that an increase in the number of plating cycles increases the thickness of $\mathrm{Sn}$ shell around the $\mathrm{Cu}$ particles. Moreover, the thicknesses of the Sn shells formed around the $\mathrm{Cu}$ core were fairly uniform.

Figure 2 shows the thickness of the Sn coating and the Sn content (in $\mathrm{wt} \%$ ) of the synthesized particles prepared with different number of plating cycles. The shell thicknesses of ten particles were measured using cross-sectional BSE images and an average value was calculated. The Sn content of each synthesized sample was determined by conducting five EDS measurements for each synthesized sample at $\times 3000$ magnification. However, the determined Sn content is likely to be slightly over-estimated since EDS measurements are meant for surface materials only. The results showed that the coating thickness and the Sn content increased linearly with the number of plating cycles.
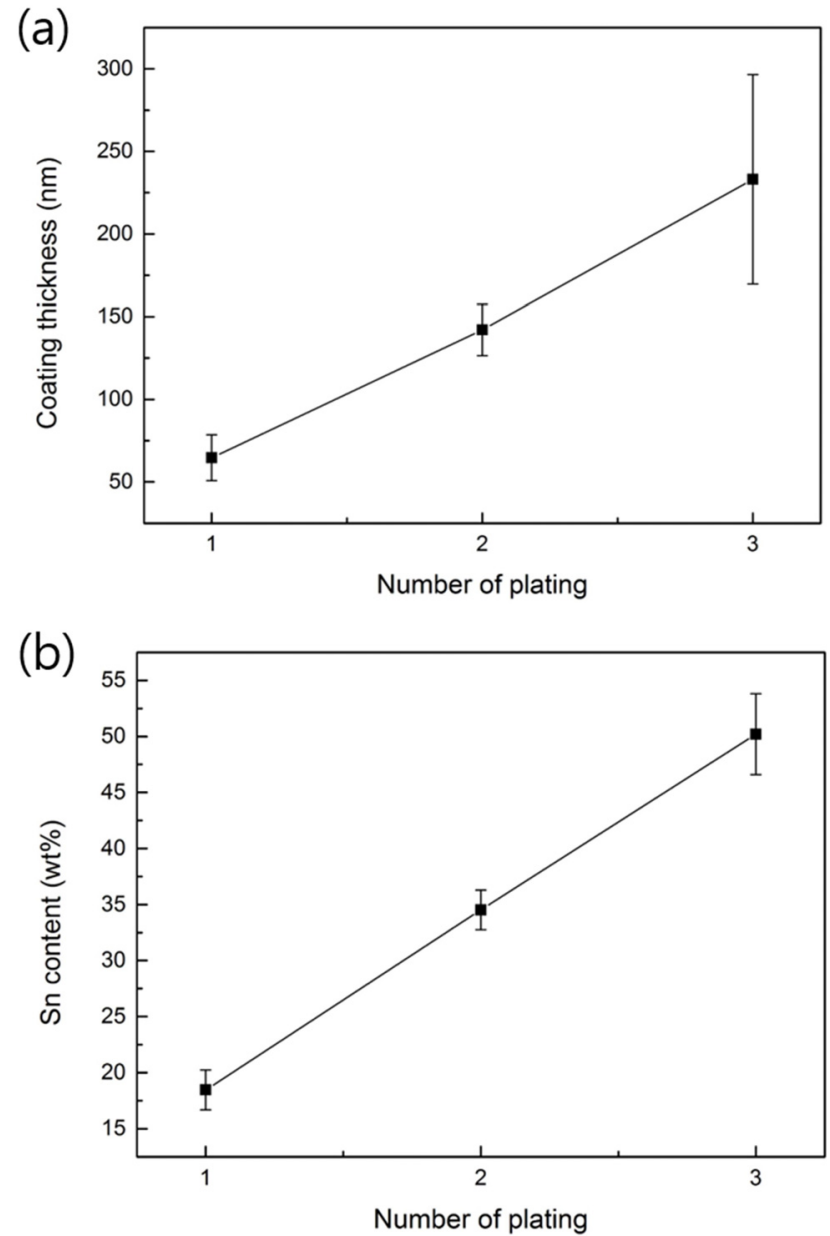

Fig. 2. (a) Sn coating thickness and (b) Sn content in Sn-coated $\mathrm{Cu}$ particles prepared with different number of plating cycles

The DSC curves of Sn-coated $\mathrm{Cu}$ particles prepared with different number of plating cycles during the first and second heating cycles are displayed in Fig. 3. The heating rate was $20^{\circ} \mathrm{C} /$ min. During the first heating cycle (Fig. 3a), the Sn-coated $\mathrm{Cu}$ particles that were plated once showed the formation of a marginal exothermic peak at $98{ }^{\circ} \mathrm{C}$ and a large and slightly broad 
exothermic peak at $162^{\circ} \mathrm{C}$. The $\mathrm{Sn}$-coated $\mathrm{Cu}$ particles that were plated twice exhibited the formation of a minor, marginal exothermic peak at $98^{\circ} \mathrm{C}$ and a large exothermic peak at $149^{\circ} \mathrm{C}$. Finally, the $\mathrm{Sn}$-coated $\mathrm{Cu}$ particles that were plated thrice also showed a minor exothermic peak at $98^{\circ} \mathrm{C}$ and a large exothermic peak at $149^{\circ} \mathrm{C}$. The first minor exothermic peak formed at $98^{\circ} \mathrm{C}$ is thought to arise due to the reaction between the Sn coating and the $\mathrm{Cu}$ core. The reaction between $\mathrm{Sn}$ and $\mathrm{Cu}$ preferentially forms the intermetallic $\mathrm{Cu}_{6} \mathrm{Sn}_{5}$ and releases the exothermic enthalpy of formation $[7,8]$. These peaks were observed at $98^{\circ} \mathrm{C}$ irrespective of the thickness of Sn coating. However, their sizes greatly depended on the thickness of the Sn shell because the amount of $\mathrm{Sn}$ reacting with $\mathrm{Cu}$ is extremely small in the case of the thin Sn shell. The second major exothermic peak is thought to arise due to continuing $\mathrm{Cu}_{6} \mathrm{Sn}_{5}$ formation and $\mathrm{Cu}_{3} \mathrm{Sn}$ formation via the reaction of the formed $\mathrm{Cu}_{6} \mathrm{Sn}_{5}$ with the $\mathrm{Cu}$ core. The formation of the $\mathrm{Cu}_{3} \mathrm{Sn}$ phase generates more heat than that of $\mathrm{Cu}_{6} \mathrm{Sn}_{5}$ [8]. The temperature at which this second peak was observed decreased from $162^{\circ} \mathrm{C}$ to $149^{\circ} \mathrm{C}$ with an increase in $\mathrm{Sn}$ thickness. Significantly, the $\mathrm{Cu}_{3} \mathrm{Sn}$ phase is produced after $\mathrm{Cu}_{6} \mathrm{Sn}_{5}$ formation. Hence, this result implies that the formation temperature of the $\mathrm{Cu}_{3} \mathrm{Sn}$ phase may increase if the thickness of the $\mathrm{Cu}_{6} \mathrm{Sn}_{5}$ phase is small.
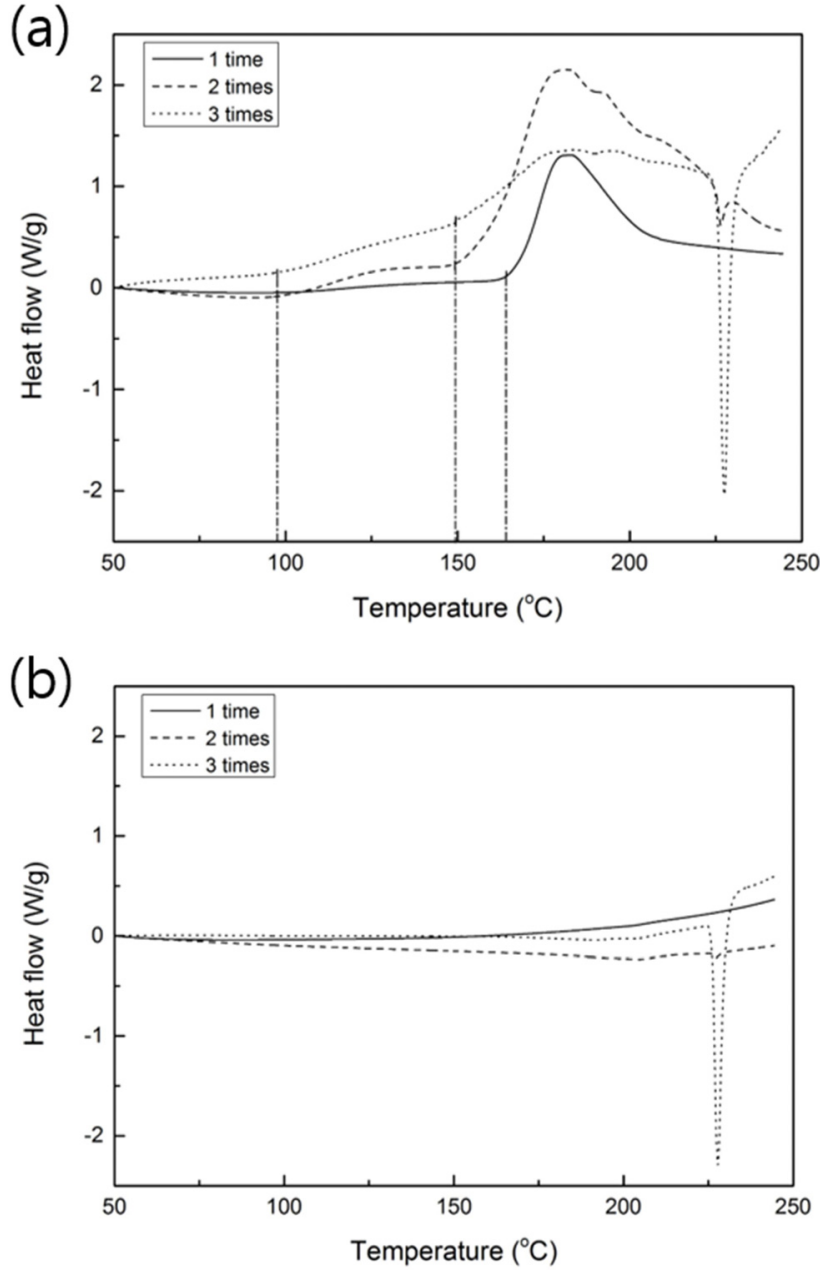

Fig. 3. DSC curves of Sn-coated $\mathrm{Cu}$ particles prepared at three different plating conditions, during the first heating (a) and second heating (b) cycles
The most significant result observed was the presence of the endothermic peaks at $232^{\circ} \mathrm{C}$ (the melting point of $\mathrm{Sn}$ ). This peak was not observed in the case of once-plated particles. However, a small peak was observed in the case of twice-plated particles. For thrice-plated particles, a remarkably pronounced endothermic peak was observed at $232^{\circ} \mathrm{C}$, indicating that a significant amount of pure $\mathrm{Sn}$ shell was still remained. These results indicate that the Sn-coated $\mathrm{Cu}$ particles that were plated thrice retain a sufficient amount of pure Sn and could be used for soldering during chip bonding.

During the second heating cycle (Fig. 3b), none of the exothermic peaks were observed and the endothermic peaks at $232^{\circ} \mathrm{C}$ were measured. The endothermic peak for the twice-plated sample was very small. However, the endothermic peak for the thrice-plated sample was still extremely pronounced, indicating that the amount of pure Sn for soldering was abundant. Hence, all further experiments were performed only with the Sn-coated $\mathrm{Cu}$ particles that were plated thrice.

The cross-sectional BSE images and the line profiles of Sncoated $\mathrm{Cu}$ particles produced using field-emission EPMA after heating at $250^{\circ} \mathrm{C}$ with different numbers of plating cycles are shown in Fig. 4. Figure 4a clearly shows the core/shell structure of $\mathrm{Cu} / \mathrm{Sn}$ in both the BSE image and the line profile. The $\mathrm{Sn}$ and $\mathrm{Cu}$ contents of similar intensity are observed at the $\mathrm{Sn} / \mathrm{Cu}$ interface, indicating the formation of a small amount of $\mathrm{Cu}-\mathrm{Sn}$ intermetallic compound. The Sn line profile abruptly changed after $10 \mathrm{~s}$ at $250^{\circ} \mathrm{C}$, as seen in Fig. $4 \mathrm{~b}$. The previous $\mathrm{Sn}$ profile has been replaced with a new Sn profile that overlaps with the $\mathrm{Cu}$ profile. Thus, Fig. $4 \mathrm{~b}$ confirmed the disappearance of the initial core-shell structure. A dimple-shaped structure was observed at the center of the new Sn profile. This could indicate the coexistence of intermetallic $\mathrm{Cu}_{6} \mathrm{Sn}_{5}$ and $\mathrm{Cu}_{3} \mathrm{Sn}$. However, a closer analysis could not be carried out to determine the nature of the intermetallic phase due to the SEM resolution limit. Also, the dimple-shaped Sn profile for the sample that was heated for $30 \mathrm{~s}$ (Fig. 4c) completely vanished. It is believed that this phenomenon is observed because the $\mathrm{Cu}_{6} \mathrm{Sn}_{5}$ phase has been transformed into the $\mathrm{Cu}_{3} \mathrm{Sn}$ phase in the center of the $\mathrm{Cu}$ particle. The samples heated for $60 \mathrm{~s}$ (Fig. 4d) and $120 \mathrm{~s}$ (Fig. not shown) exhibited no noticeable changes.

The XRD results of $\mathrm{Sn}$-coated $\mathrm{Cu}$ powder heated at $250^{\circ} \mathrm{C}$ at different times are as shown in Fig. 5. Trace amounts of $\mathrm{Cu}_{6} \mathrm{Sn}_{5}$ and $\mathrm{Cu}_{3} \mathrm{Sn}$ intermetallic compounds as well as $\mathrm{Sn}$ and $\mathrm{Cu}$ were recorded. As reaction time approached $10 \mathrm{~s}$, the main peaks of $\mathrm{Sn}$ and $\mathrm{Cu}$ almost disappeared and a prominent $\mathrm{Cu}_{6} \mathrm{Sn}_{5}$ peak and an inconspicuous $\mathrm{Cu}_{3} \mathrm{Sn}$ peak appeared. The main peak of $\mathrm{Cu}_{3} \mathrm{Sn}$ became more defined and pronounced when the reaction time increased to $30 \mathrm{~s}$. These results show the possibility of using these synthesized Sn-coated $\mathrm{Cu}$ particles (plated thrice) for rapid chip bonding by TLP. The relative intensity of the $\mathrm{Cu}_{3} \mathrm{Sn}$ peak increased when the reaction time was increased to $60 \mathrm{~s}$ or $120 \mathrm{~s}$. These results demonstrate that, with the increase in the reaction time from $10 \mathrm{~s}$ to $120 \mathrm{~s}$, the preferentially formed intermetallic $\mathrm{Cu}_{6} \mathrm{Sn}_{5}$ gradually transforms into $\mathrm{Cu}_{3} \mathrm{Sn}$.

Finally, die bonding was performed using a paste that mainly contained the $\mathrm{Sn}$-coated $\mathrm{Cu}$ powder. Figure 6 shows the 

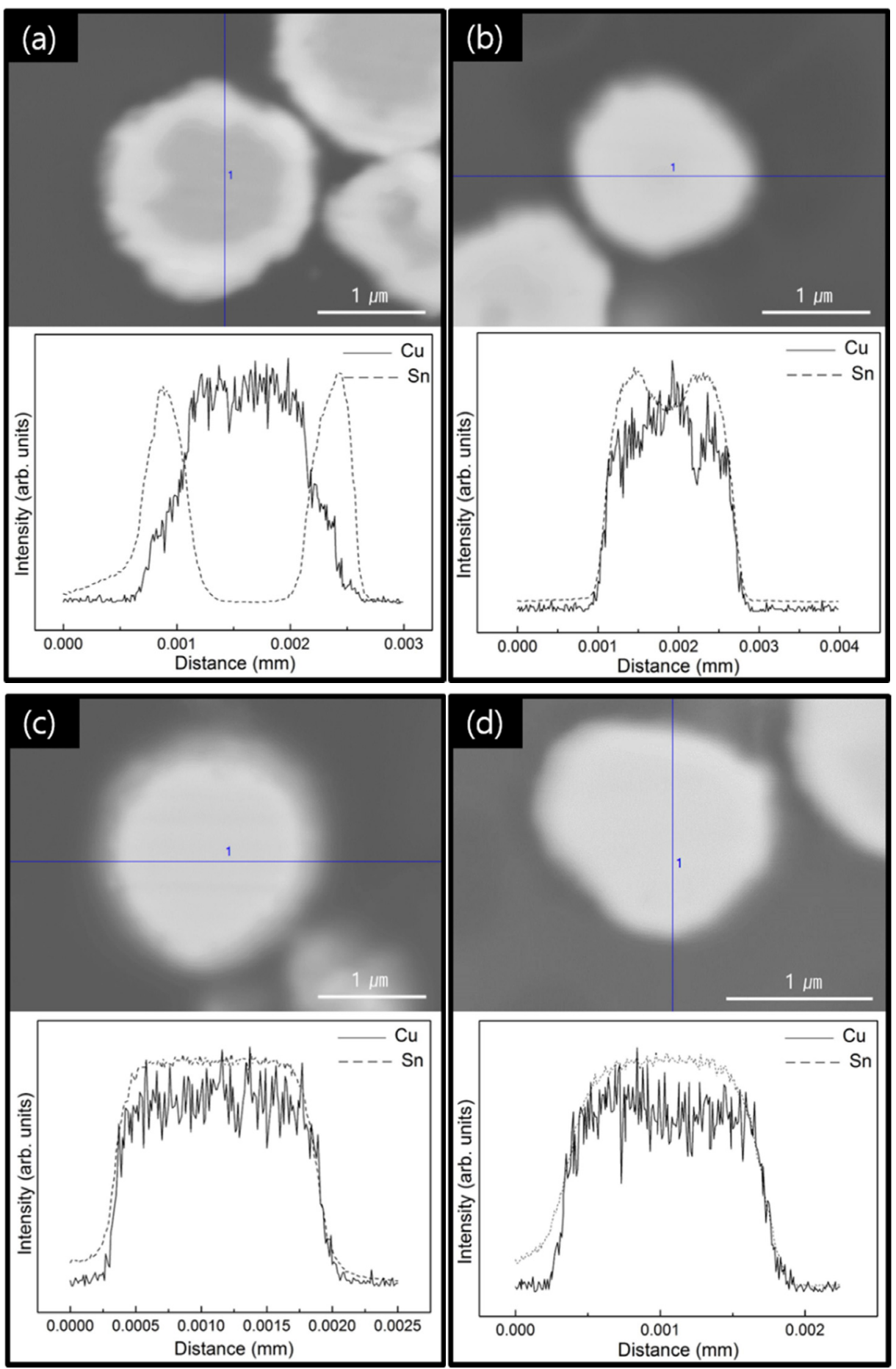

Fig. 4. Cross-sectional BSE images and line profiles of Sn-coated $\mathrm{Cu}$ particles obtained using field-emission EPMA after heating at $250^{\circ} \mathrm{C}$ for different durations: (a) as-prepared, (b) $10 \mathrm{~s}$, (c) $30 \mathrm{~s}$, and (d) $60 \mathrm{~s}$

cross-sectional BSE images of bondlines formed after die bonding at $250^{\circ} \mathrm{C}$ using a slight bonding pressure of around $0.1 \mathrm{MPa}$ at different heating times. Both the die and substrate were plated with $\mathrm{Au}$. The paste solidified abruptly after heating at $250^{\circ} \mathrm{C}$. When the Sn-coated Cu particles were heated for $10 \mathrm{~s}$, there was no indication of extensive physical network formation or a connection between the particles and the Au surfaces. This unpredictable outcome could be a result of the TLP sintering process failing to be completed. Owing to the low thermal conductivity of the paste, the heating time of $10 \mathrm{~s}$ may be insufficient to melt
Sn. This interpretation can be verified from the fact that most Sn-coated Cu particles maintained the core-shell structure even after the heating for $10 \mathrm{~s}$. However, when the heating time was increased to $30 \mathrm{~s}$, the bonding of $\mathrm{Sn}$-coated $\mathrm{Cu}$ particles to the $\mathrm{Au}$ surface and connections between particles were simultaneously achieved. The microstructure was continuously monitored and no notable microstructural changes were observed when the heating time was changed from $30 \mathrm{~s}$ to $120 \mathrm{~s}$. When compared to results in Fig. 4 and 5, a major discrepancy in the microstructure of $\mathrm{Sn}$-coated $\mathrm{Cu}$ particles was observed: i.e., even after heating, 
(a)

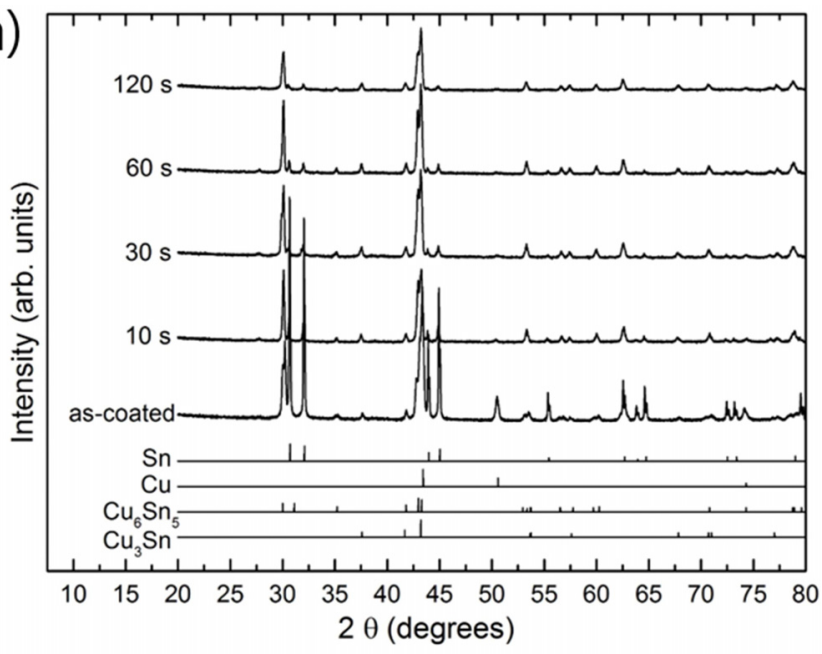

(b)

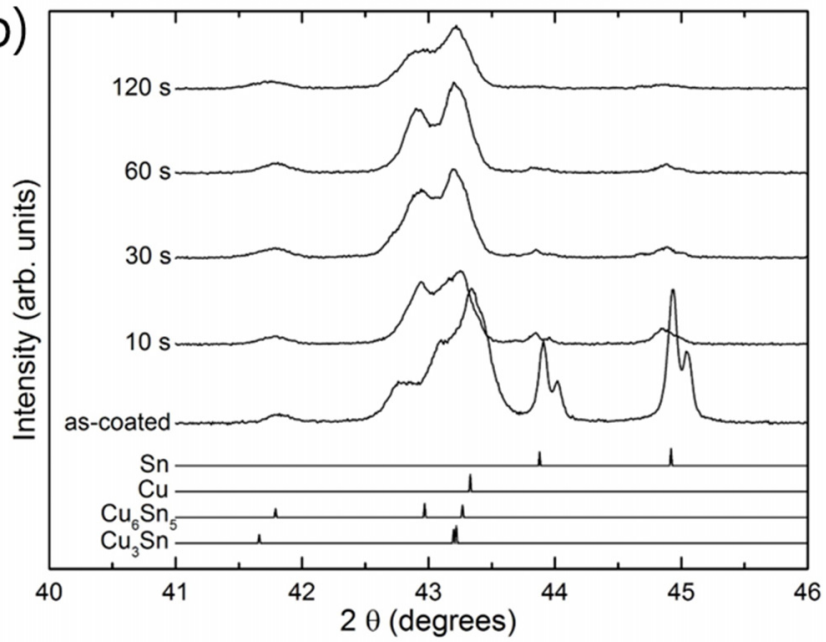

Fig. 5. XRD results of $\mathrm{Sn}$-coated $\mathrm{Cu}$ powder heated at $250^{\circ} \mathrm{C}$ for different durations: (a) full-scan range of $20^{\circ}-80^{\circ}$ and (b) magnification narrow range of $41^{\circ}-46^{\circ}$

some particles maintained their core-shell structure. The Sn shell converted to the $\mathrm{Cu}_{6} \mathrm{Sn}_{5}$ phase immediately after melting, similar to previous results. However, unlike the conditions seen in Fig. 4 and 5, the $\mathrm{Sn}$ in the $\mathrm{Cu}_{6} \mathrm{Sn}_{5}$ diffused not only into the original $\mathrm{Cu}$ core but also to the newly connected neighboring particles formed due to the extended structure of the network. Thus, $\mathrm{Sn}$ diffused in all directions from the $\mathrm{Cu}$ core to each and every point of the linked Sn shells. This diluted diffusion of $\mathrm{Sn}$ greatly reduced the growth rate of $\mathrm{Cu}_{6} \mathrm{Sn}_{5}$ phase and increased the time required to deplete the $\mathrm{Cu}$ core. The core-shell structures were also dominant among the $\mathrm{Sn}$-coated $\mathrm{Cu}$ particles that were bonded to the Au surface. This was due to the depletion of $\mathrm{Sn}$ caused by the reaction with $\mathrm{Au}$ to form $\mathrm{AuSn}_{4}$ intermetallic compound.

\section{Conclusions}

The Sn-coated Cu particles were successfully synthesized using the proposed wet plating method. The particles best suited for the TLP sintering process were prepared by plating
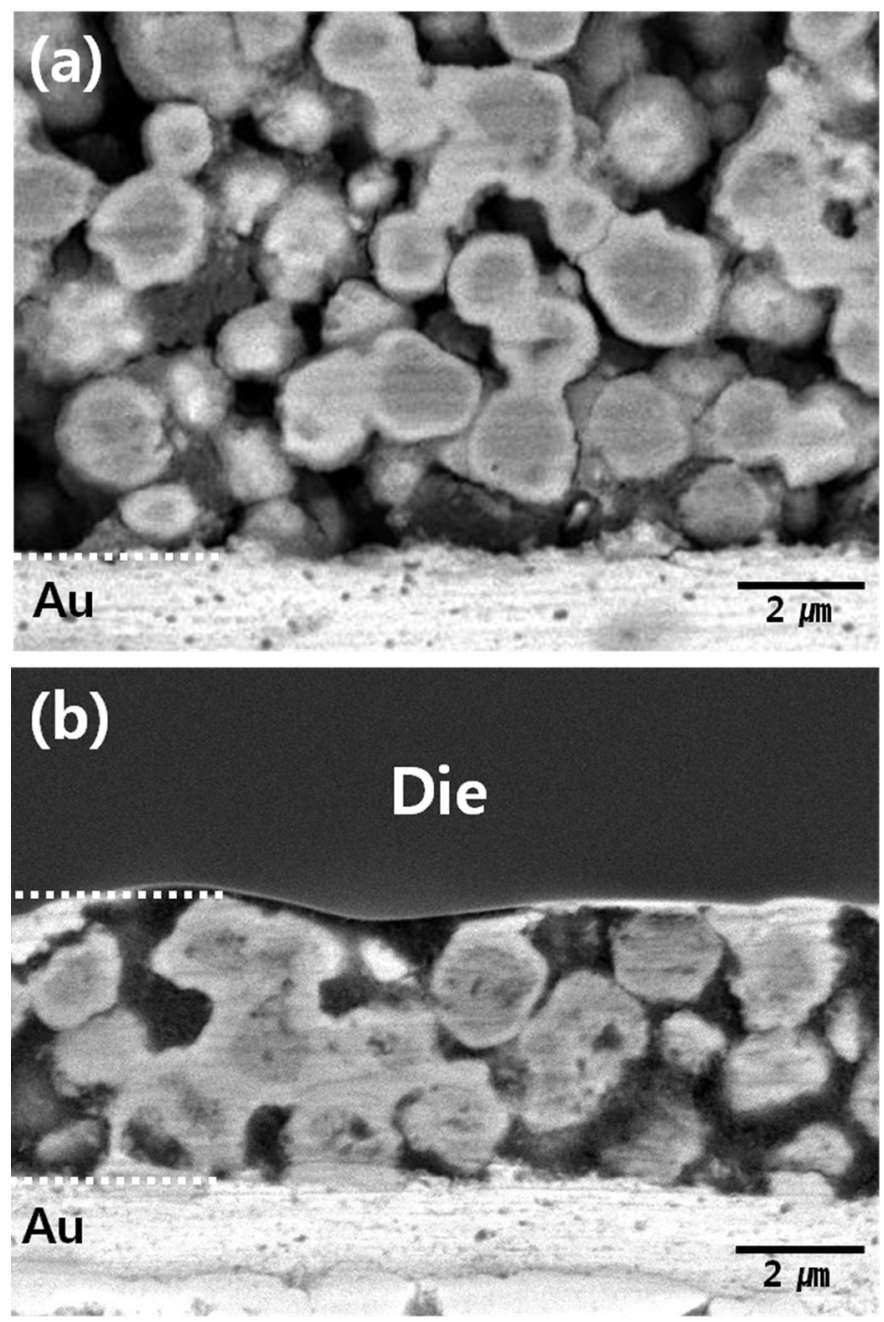

Fig. 6. Cross-sectional BSE images of bondlines formed after die bonding using a Sn-coated $\mathrm{Cu}$ paste at $250^{\circ} \mathrm{C}$ for different heating durations: (a) $10 \mathrm{~s}$ and (b) $30 \mathrm{~s}$

$\mathrm{Cu}$ particles with $\mathrm{Sn}$ three times. DSC measurements showed that the reaction between the $\mathrm{Sn}$ shell and $\mathrm{Cu}$ core initiates at $98^{\circ} \mathrm{C}$ and subsequent reactions take place at $149^{\circ} \mathrm{C}$ at an accelerated pace. Moreover, a striking endothermic peak at $232^{\circ} \mathrm{C}$ was also observed, which confirmed the formation of sufficient amount of Sn. It was also interesting to note that heating of Sncoated $\mathrm{Cu}$ particles for just $10 \mathrm{~s}$ at $250^{\circ} \mathrm{C}$ destroyed the initial core-shell structure and encouraged the formation of $\mathrm{Cu}-\mathrm{Sn}$ intermetallics. The die bonding was also successfully performed at $250^{\circ} \mathrm{C}$ under the bonding pressure of around $0.1 \mathrm{MPa}$ using a paste mainly containing the $\mathrm{Sn}$-coated $\mathrm{Cu}$ powder. In contrast to the results obtained when $\mathrm{Sn}$-coated $\mathrm{Cu}$ particles were directly heated, indirect heating for $10 \mathrm{~s}$ through the paste did not result in the formation of microstructures of the bondline, due to insufficient TLP sintering. Increasing bonding time to $30 \mathrm{~s}$ facilitated the bonding of $\mathrm{Sn}$-coated $\mathrm{Cu}$ particles to the $\mathrm{Au}$ surface and also increased the probability of network formation between particles. 
1148

\section{Acknowledgment}

This work was supported by the Materials \& Components Technology Development Program (10047681) funded by the Ministry of Trade, Industry \& Energy (MI, Korea)

\section{REFERENCES}

[1] J. Yin, Z. Liang, J.D. Wyk, IEEE Trans. Power Electron. 22, 392 (2007).
[2] J.E. Lee, K.S. Kim, K. Suganuma, J. Takenaka, K. Hagio, Mater. Trans. 46, 2413 (2005).

[3] E. Halonen, T. Viiru, K. Östman, A.L. Cabezas, M. Mäntysalo, IEEE Trans. Compon. Packag. Manuf. Technol. 3, 350 (2013).

[4] N.S. Bosco, F.W. Zok, Acta Mater. 53, 2019 (2005).

[5] J.F. Li, P.A. Agyakwa, C.M. Johnson, Acta Mater. 59, 1198 (2011).

[6] M.S. Park, S.L. Gibbons, R. Arróyave, Acta Mater. 60, 6278 (2012).

[7] W. Gierlotka, S.W. Chen, S.K. Lin, J. Mater. Res. 22, 3158 (2007).

[8] H. Flandorfer, U. Saeed, C. Luef, A. Sabbar, H. Ipser, Thermochim. Acta 459, 34 (2007). 